\title{
Notable and Obvious Ketene Substituent-Dependent Effect of Temperature on the Stereoselectivity in the Staudinger Reaction
}

\author{
Bonan Li, Yikai Wang, Da-Ming Du, and Jiaxi Xu*
}

\begin{abstract}
Beijing National Laboratory for Molecular Sciences (BNLMS), Key Laboratory of Bioorganic Chemistry and Molecular Engineering of Ministry of Education, College of Chemistry and Molecular Engineering,

Peking University, Beijing 100871, People’s Republic of China

jxxu@pku.edu.cn
\end{abstract}

\section{Supplemental Materials}

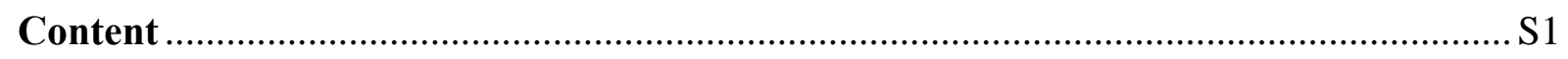

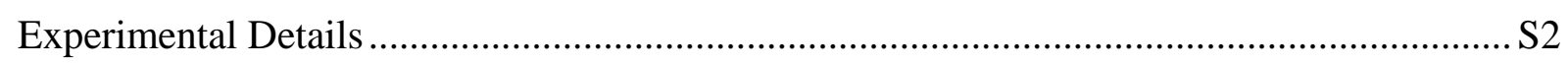

Copies of ${ }^{1} \mathrm{H}$ and ${ }^{13} \mathrm{C}$ NMR Spectra of the Unknown Products .......................................... S5

Copies of the Representative ${ }^{1} \mathrm{H}$ NMR Spectra for Determination of Cis/Trans Ratios........ S11 


\section{Experimental Details}

General. S-Phenyl 2-diazoethanethioate $\mathbf{1}^{1}$ and imines $\mathbf{2 a - c ^ { 2 , 3 , 4 }}$ were prepared according to published procedures. Toluene, xylene, and 1,3,5-mesitylene were refluxed with sodium and freshly distilled prior to use. All reactions were performed under a nitrogen atmosphere. The reaction temperature was controlled carefully with a fine temperature controller in a big water-bath with a large amount of water, covered with paraffin oil, and a thick asbestos coating outside the bath within less than $\pm 0.5{ }^{\circ} \mathrm{C}$, in the temperature region of $40-90{ }^{\circ} \mathrm{C}$, in a big oil-bath with a large amount of oil and a thick asbestos coating outside the bath within less than $\pm 2 \sim 3{ }^{\circ} \mathrm{C}$ in the temperature region of $100-150{ }^{\circ} \mathrm{C} .{ }^{1} \mathrm{H}$ and ${ }^{13} \mathrm{C}$ NMR spectra were recorded in $\mathrm{CDCl}_{3}$ with TMS as an internal standard. All known products $3,4, \mathbf{5}, \mathbf{6}, \mathbf{7}, \mathbf{8}, \mathbf{9}, \mathbf{1 0}, \mathbf{1 1}, \mathbf{1 2}, \mathbf{1 3}$,

$14,15,16,19,20,23$, and 24 show the identical analytic data to reported data in the literatures. ${ }^{3,4,5,6,7}$

\section{Determination of the cis/trans Ratios of the Crude $\beta$-Lactam Products.}

1. For the reaction of propionyl chloride (1a) with imine $\mathbf{2 a}$, the cis/trans ratios were obtained by the integrals of the corresponding $\mathrm{C}(4)$ protons of $\beta$-lactams 3 and 4 in ${ }^{1} \mathrm{H}$ NMR spectra (the proton of cis-isomer 3 appears at about $4.87 \mathrm{ppm}$, while the proton of trans-isomer 4 appears at $4.22 \mathrm{ppm}$ ) of the crude reaction mixture. (Propionyl chloride and propionic acid have peaks at 2.93 and $2.38 \mathrm{ppm}$, respectively.)

2. For the reaction of phenylacetyl chloride (1b) and imine 2a, the cis/trans ratios were obtained by the integrals of the corresponding $\mathrm{C}(3)$ and/or $\mathrm{C}(4)$ protons of $\beta$-lactams 5 and 6 in ${ }^{1} \mathrm{H}$ NMR spectra (the protons of cis-isomer 5 appear at 5.17 and 4.88 ppm, while the protons of trans-isomer $\mathbf{6}$ appear at 4.61 and $4.07 \mathrm{ppm}$ ) of the crude reaction mixture after washing with saturated sodium bicarbanate to remove unreacted phenylacetyl chloride and phenylacetic acid. (Phenylacetyl chloride and phenylacetic acid have peaks at 4.08 and $3.64 \mathrm{ppm}$, respectively.)

3. For the reaction of phenoxyacetyl chloride (1c) and imine $\mathbf{2 b}$, the cis/trans ratios were obtained by the integrals of the $\mathrm{C}(3)$ proton of $\beta$-lactams 7 and the $\mathrm{C}(4)$ proton of $\beta$-lactam 8 in ${ }^{1} \mathrm{H}$ NMR spectra (the $\mathrm{C}(3)$ proton of cis-isomer 7 appears at $5.32 \mathrm{ppm}$, while the $\mathrm{C}(4)$ proton of trans-isomer 8 appears at $4.49 \mathrm{ppm}$, while the peaks of the $\mathrm{C}(4)$ proton of $\beta$-lactams 7 and the $\mathrm{C}(4)$ proton of $\beta$-lactam 8 appear near $4.89 \mathrm{ppm}$, unseparable) of the crude reaction mixture after washing with saturated sodium bicarbanate to remove unreacted phenoxyacetyl chloride and phenoxyacetic acid, which have peaks at 4.88 and $4.67 \mathrm{ppm}$, respectively, affecting the accurate determination.

\footnotetext{
${ }^{1}$ Danheiser, R. L.; Okamoto, I.; Lawlor, M. D.; Lee, T. W. Org. Synth. Vol. 80, 160-171.

2 Linder, M. R.; Frey, W. U.; Podlech, J. J. Chem. Soc., Perkin Trans. 1 2001, 2566-2577.

Jiao, L.; Liang, Y.; Xu, J. X. J. Am. Chem. Soc. 2006, 128, 6060-6069.

${ }^{4}$ Ohmori, H.; Maeda, H.; Kikuoka, M.; Maki, T.; Masui, M. Tetrahedron 1991, 47, 767-776.

${ }^{5}$ Ejaegher, Y.; Denolf, B.; Stevens, C. V.; De Kimpe, N. Synthesis 2005, 193-198.

${ }^{6}$ Abd-Elzaher, M. M.; Fischer, H. J. Organomet. Chem. 1999, 588, 235-241.

${ }^{7}$ Wang, Y. K.; Liang, Y.; Jiao, L.; Du, D. M.; Xu, J. X. J. Org. Chem. 2006, 71, 6983-6990.
} 
4. For the reaction of chloroacetyl chloride (1d) and imine 2a, the cis/trans ratios were obtained by the integrals of the corresponding $\mathrm{C}(3)$ and $\mathrm{C}(4)$ protons of $\beta$-lactams 9 and $\mathbf{1 0}$ in ${ }^{1} \mathrm{H}$ NMR spectra (the protons of cis-isomer 9 appear at 5.07 and $5.10 \mathrm{ppm}$, while the protons of trans-isomer 10 appear at 4.45 and $4.63 \mathrm{ppm}$ ) of the crude reaction mixture. (Chloroacetyl chloride and chloroacetic acid have peaks at 4.52 and $4.15 \mathrm{ppm}$, respectively.)

5. For the reaction of phthalimidoacetyl chloride (1e) and imine $\mathbf{2 b}$, the cis/trans ratios were obtained by the integrals of the corresponding $\mathrm{C}(3)$ and $\mathrm{C}(4)$ protons of $\beta$-lactams 11 and $\mathbf{1 2}$ in ${ }^{1} \mathrm{H}$ NMR spectra (the protons of cis-isomer 11 appear at 5.03 and $5.36 \mathrm{ppm}$, while the protons of trans-isomer 12 appear at 4.92 and $5.09 \mathrm{ppm}$ ) of the crude reaction mixture after washing with saturated sodium bicarbanate to remove unreacted phthalimidoacetyl chloride and phthalimidoacetic acid. (Phthalimidoacetyl chloride and phthalimidoacetic acid have peaks at 4.84 and $4.35 \mathrm{ppm}$, respectively.)

6. For the reactions of phenylthioacetyl chloride (1f) and $S$-phenyl 2-diazoethanethioate (1g) with imine 2a, the cis/trans ratios were obtained by the integrals of the corresponding $\mathrm{C}(3)$ and $\mathrm{C}(4)$ protons of $\beta$-lactams 13 and 14 in ${ }^{1} \mathrm{H}$ NMR spectra (the protons of cis-isomer 13 appear at 4.91 and 5.17 ppm, while the protons of trans-isomer $\mathbf{1 4}$ appear at 4.02 and $4.45 \mathrm{ppm}$ ) of the crude reaction mixture. ( $S$-Phenyl 2-diazoethanethioate has a peak at $5.26 \mathrm{ppm}$. Phenylthioacetyl chloride and phenylthioacetic acid have peaks at 3.62 and $3.69 \mathrm{ppm}$, respectively.)

7. For the reaction of phenylthioacetyl chloride (1f) with imine $\mathbf{2 b}$, the cis/trans ratios were obtained by the integrals of the corresponding $\mathrm{C}(3)$ and $\mathrm{C}(4)$ protons of $\beta$-lactams 15 and $\mathbf{1 6}$ in ${ }^{1} \mathrm{H}$ NMR spectra (the protons of cis-isomer 15 appear at 4.95 and $5.71 \mathrm{ppm}$, while the protons of trans-isomer 16 appear at 4.28 and $4.02 \mathrm{ppm}$ ) of the crude reaction mixture. (Phenylthioacetyl chloride and phenylthioacetic acid have peaks at 3.62 and $3.69 \mathrm{ppm}$, respectively.)

8. For the reaction of 4-methoxyphenylacetyl chloride (1h) with imine $\mathbf{2} \mathbf{b}$, the cis/trans ratios were obtained by the integrals of the corresponding $\mathrm{C}(3)$ and $\mathrm{C}(4)$ protons of $\beta$-lactams $\mathbf{1 7}$ and $\mathbf{1 8}$ in ${ }^{1} \mathrm{H}$ NMR spectra (the protons of cis-isomer $\mathbf{1 7}$ appear at 4.95 and $4.67 \mathrm{ppm}$, while the protons of trans-isomer $\mathbf{1 8}$ appear at 4.39 and $4.01 \mathrm{ppm}$ ) of the crude reaction mixture after washing with saturated sodium bicarbanate to remove unreacted 4-methoxyphenylacetyl chloride and 4-methoxyphenylacetic acid. (4-Methoxyphenylacetyl chloride and 4-methoxyphenylacetic acid have peaks at 4.02 and $3.68 \mathrm{ppm}$, respectively, for $\mathrm{CH}_{2}$ group, 3.83 and 3.80 ppm for $\mathrm{MeO}$ group.)

9. For the reaction of phenylacetyl chloride (1b) and imine $\mathbf{2 b}$, the cis/trans ratios were obtained by the integrals of the corresponding $\mathrm{C}(3)$ and/or $\mathrm{C}(4)$ protons of $\beta$-lactams 19 and 20 in ${ }^{1} \mathrm{H}$ NMR spectra (the protons of cis-isomer 19 appear at 5.00 and 4.74 ppm, while the protons of trans-isomer 20 appear at 4.45 and $4.07 \mathrm{ppm}$ ) of the crude reaction mixture after washing with saturated sodium bicarbanate to 
remove unreacted phenylacetyl chloride and phenylacetic acid. (Phenylacetyl chloride and phenylacetic acid have peaks at 4.08 and 3.64 ppm, respectively.)

10. For the reaction of 4-nitrophenylacetyl chloride (1i) with imine $\mathbf{2} \mathbf{b}$, the cis/trans ratios were obtained by the integrals of the corresponding $\mathrm{C}(3)$ and $\mathrm{C}(4)$ protons of $\beta$-lactams 21 and 22 in ${ }^{1} \mathrm{H}$ NMR spectra (the protons of cis-isomer 21 appear at 5.05 and $4.78 \mathrm{ppm}$, while the protons of trans-isomer 22 appear at 4.47 and $4.17 \mathrm{ppm}$ ) of the crude reaction mixture. (4-nitrophenylacetyl chloride and 4-nitrophenylacetic acid have peaks at 4.30 and $3.75 \mathrm{ppm}$, respectively.)

11. For the reaction of 4-nitrophenylacetyl chloride (1i) with imine 2a, the cis/trans ratios were obtained by the integrals of the corresponding $\mathrm{C}(3)$ and $\mathrm{C}(4)$ protons of $\beta$-lactams 23 and 24 in ${ }^{1} \mathrm{H}$ NMR spectra (the protons of cis-isomer 23 appear at 5.24 and 4.95 ppm, while the protons of trans-isomer $\mathbf{2 4}$ appear at 4.65 and $4.20 \mathrm{ppm}$ ) of the crude reaction mixture after washing with saturated sodium bicarbanate to remove unreacted 4-nitrophenylacetyl chloride and 4-nitrophenylacetic acid. (4-nitrophenylacetyl chloride and 4-nitrophenylacetic acid have peaks at 4.30 and $3.75 \mathrm{ppm}$, respectively.) 
Copies of ${ }^{1} \mathrm{H}$ and ${ }^{13} \mathrm{C}$ NMR Spectra of the Unknown Products

( \pm )-cis-1-Isopropyl-3-(4-methoxyphenyl)-4-(4-methoxyphenyl)azetidin-2-one (17)<smiles>COc1ccc([C@H]2C(=O)N(PC)[C@H]2c2ccc(OC)cc2)cc1</smiles>

LBN2436 C1S

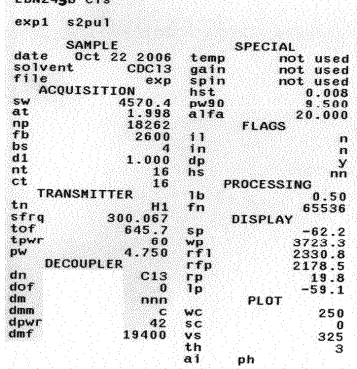
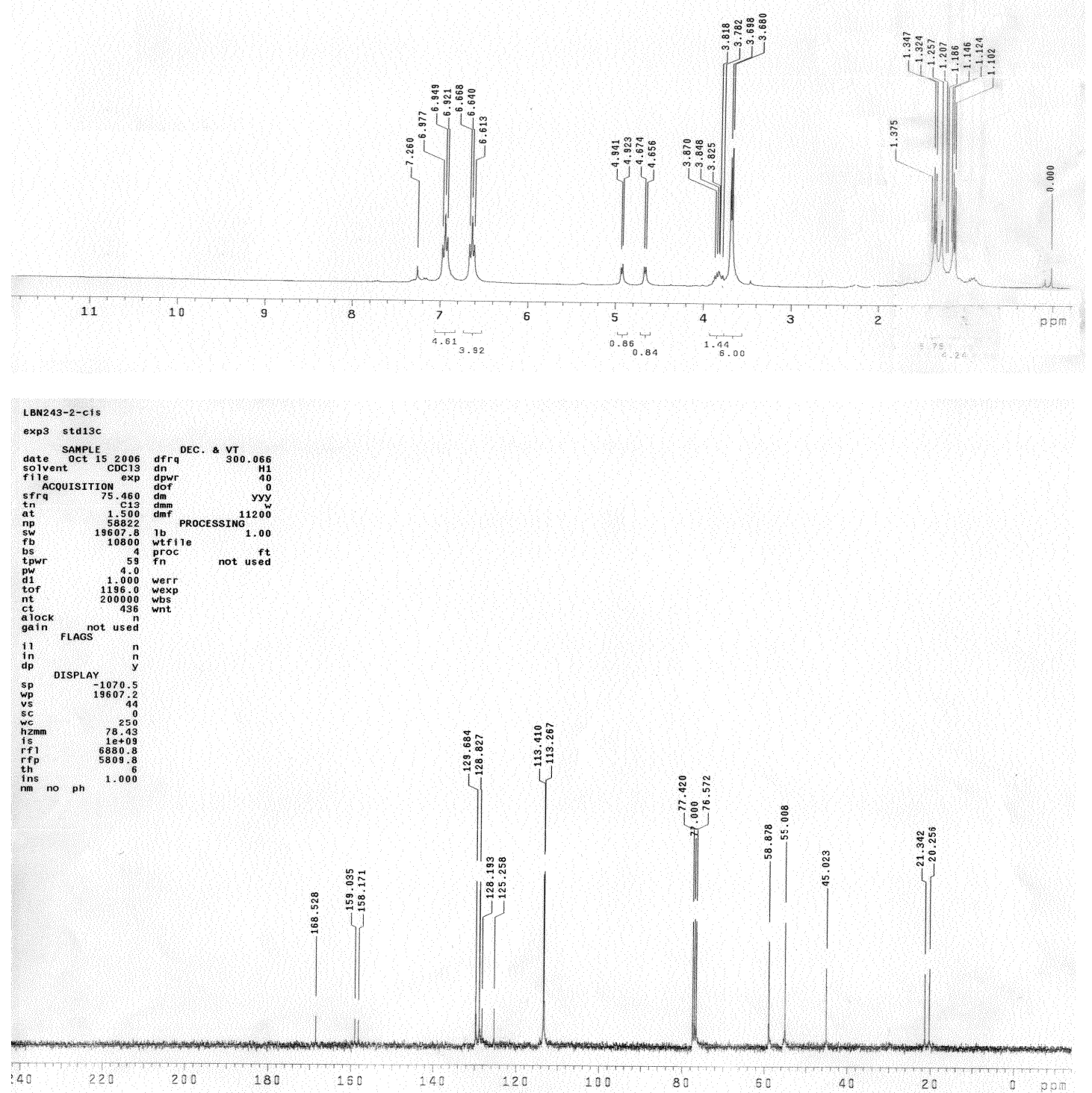
( \pm )-trans-1-Isopropyl-3-(4-methoxyphenyl)-4-(4-methoxyphenyl)azetidin-2-one (18)<smiles>CCCN1C(=O)[C@@H](c2ccc(OC)cc2)[C@H]1c1ccc(OC)cc1</smiles>

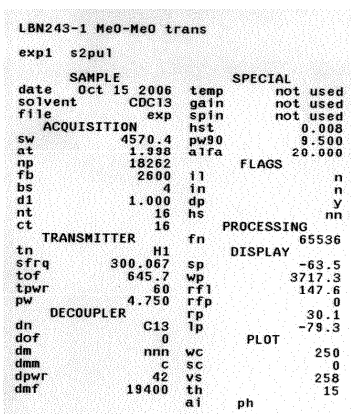

$( \pm)$
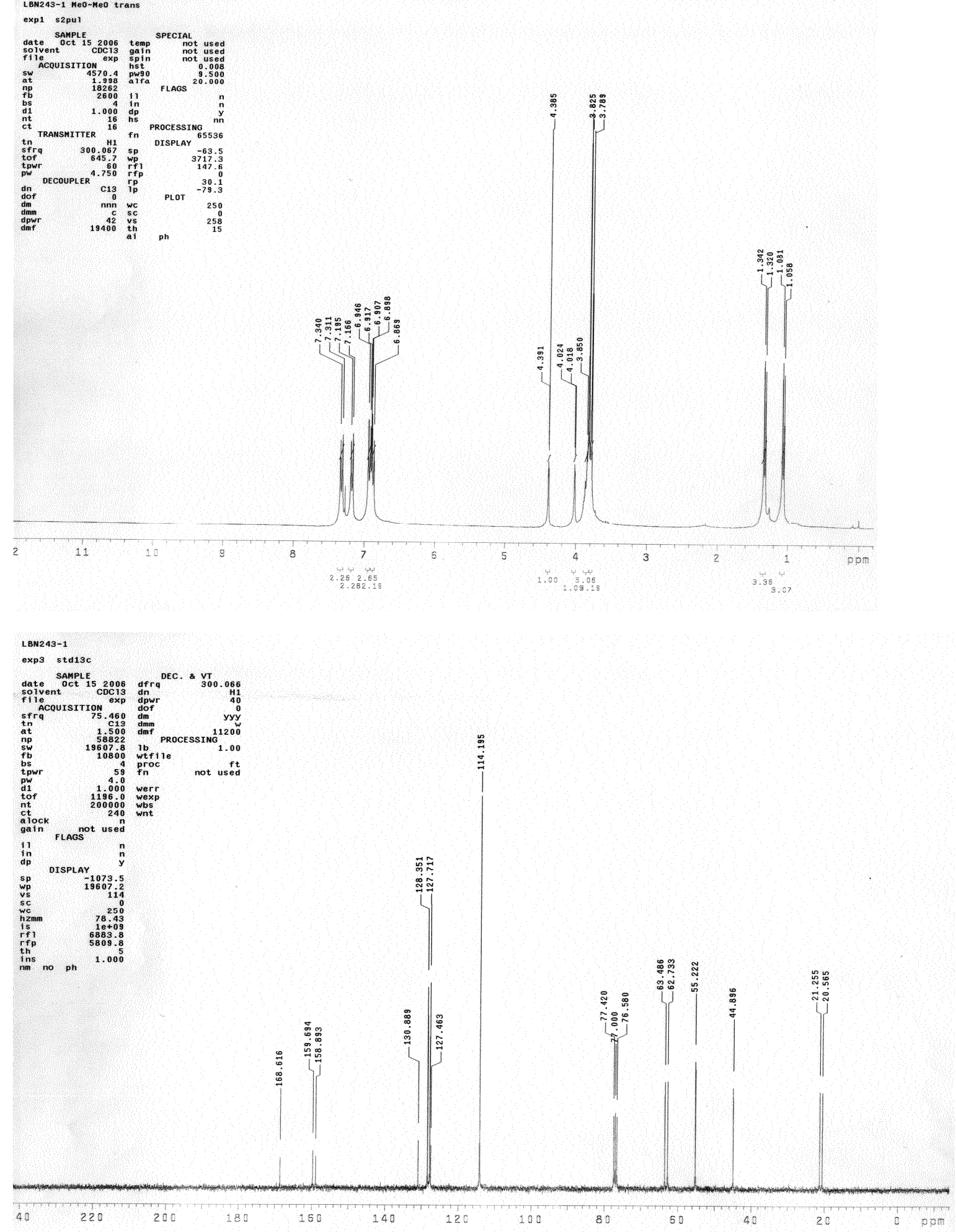
( \pm )-trans-1-Isopropyl-4-(4-methoxyphenyl)-3-(4-nitrophenyl)azetidin-2-one (22)<smiles>CCCN1C(=O)[C@@H](c2ccc([N+](=O)[O-])cc2)[C@H]1c1ccc(OC)cc1</smiles>

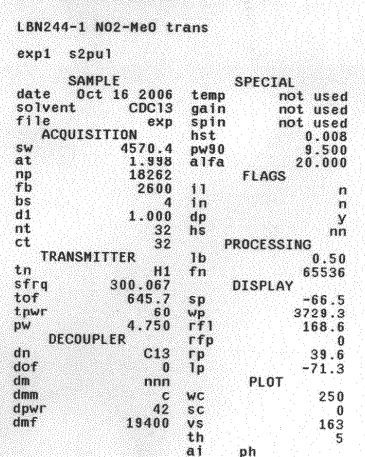
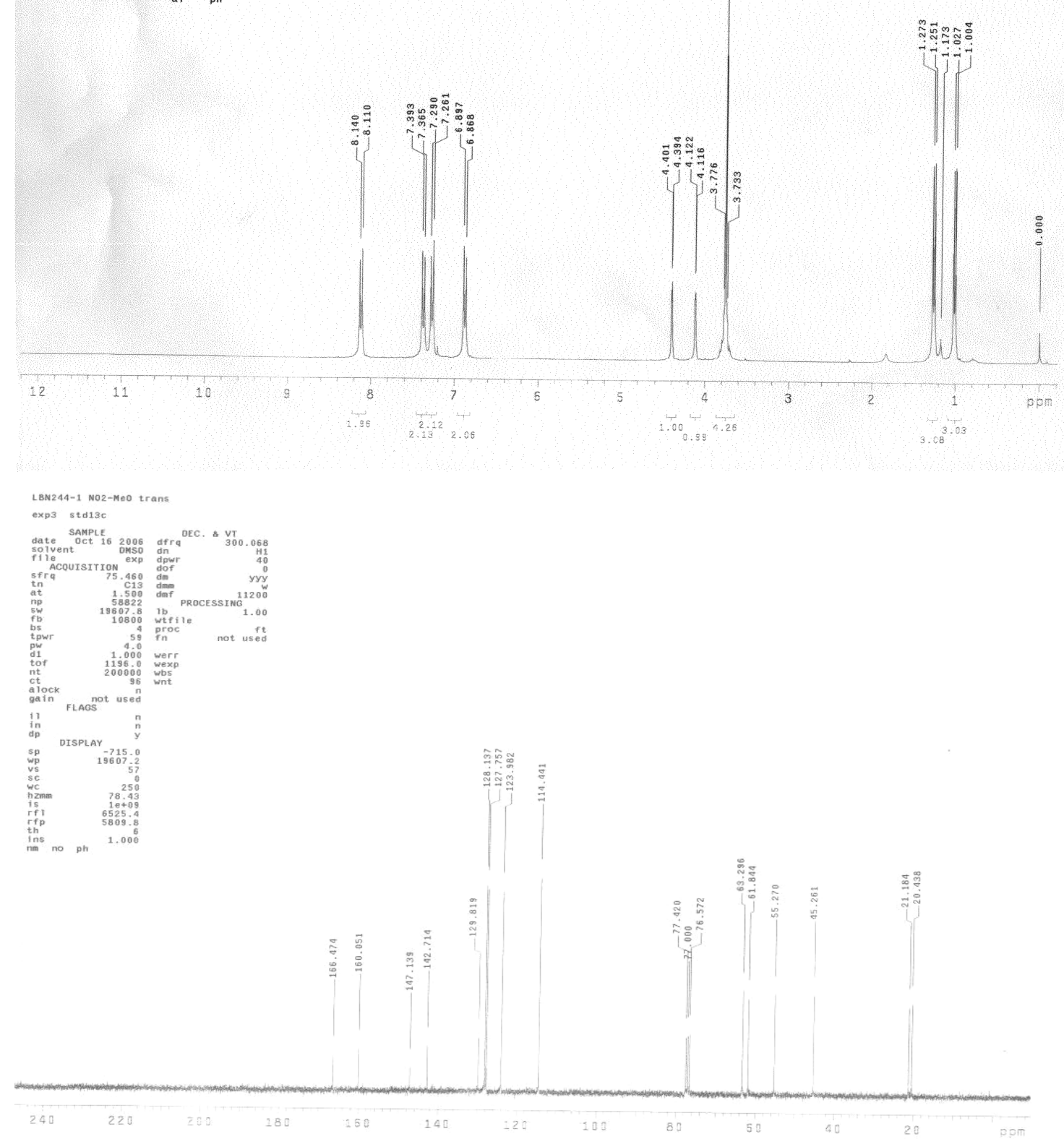
( \pm )-trans-2-Methyl-4-nitro-azeto[1,2- $d]$ dibenzo $[b, f]$ oxazepin-1-one (25a)

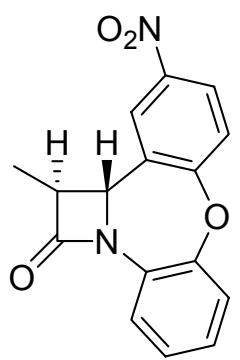

$( \pm)$

LBN152C Me-CImine-NO2 1500 C

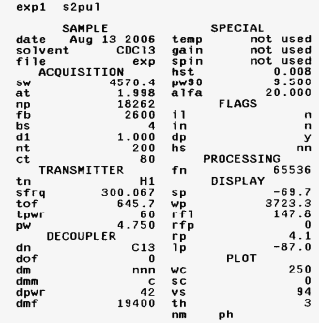

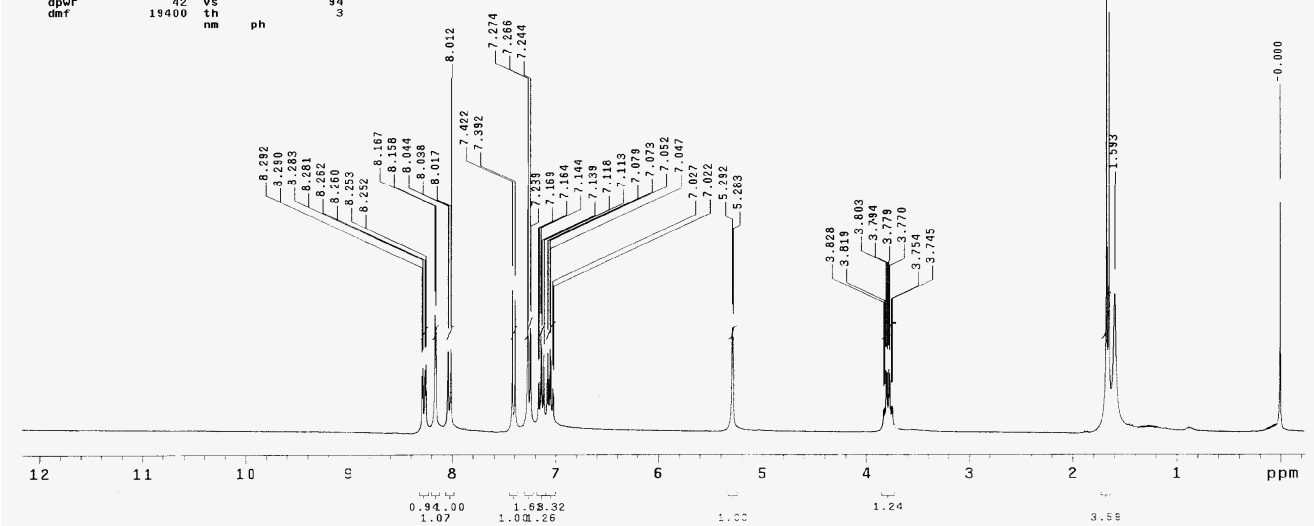

LBN152C Me-CImine-HO2 $1500 \mathrm{C}$

$\begin{array}{ll}\text { exp3 } & \text { sta13c } \\ & \text { SAAPLE }\end{array}$
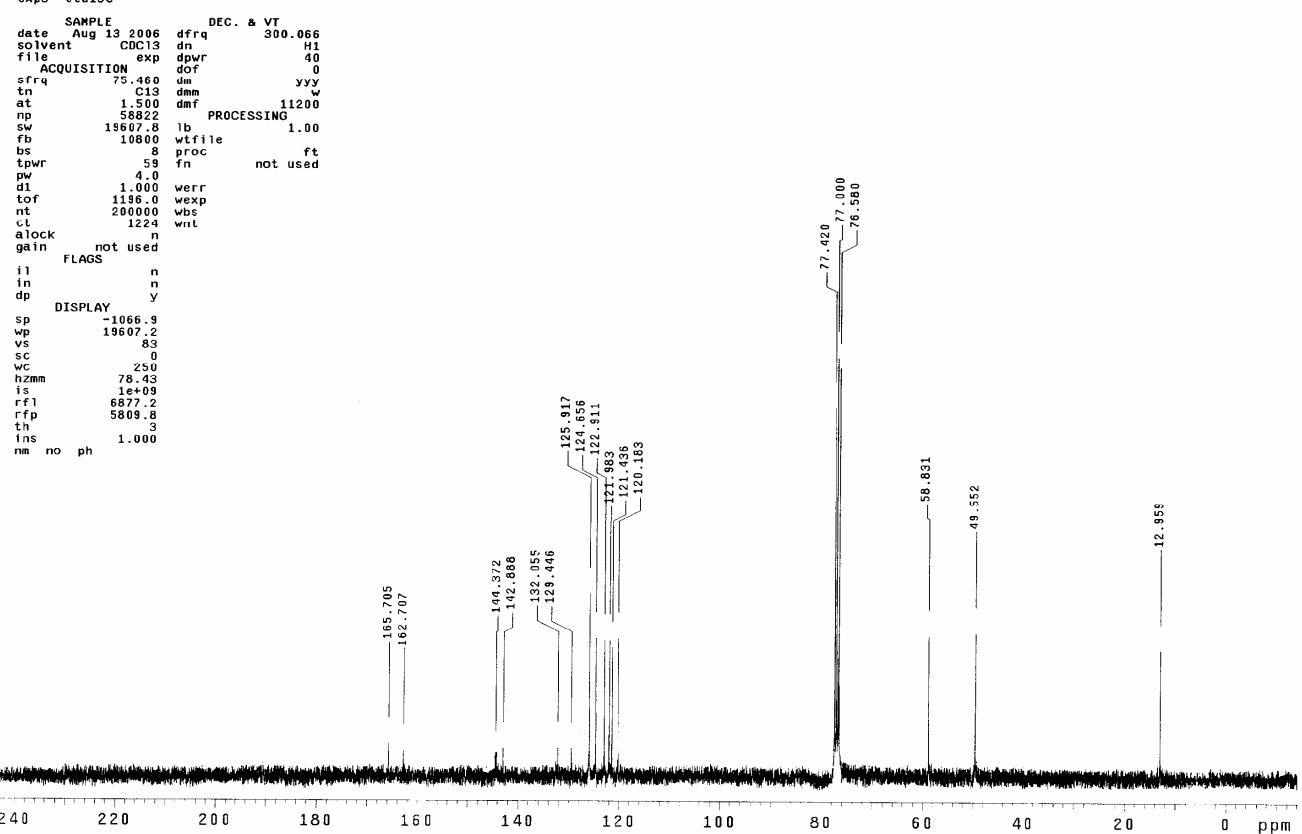
( \pm )-trans-2-Chloro-4-nitro-azeto[1,2- $d]$ dibenzo $[b, f]$ oxazepin-1-one (25b)

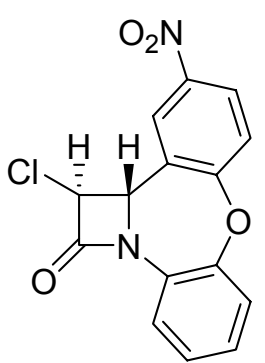

$( \pm)$
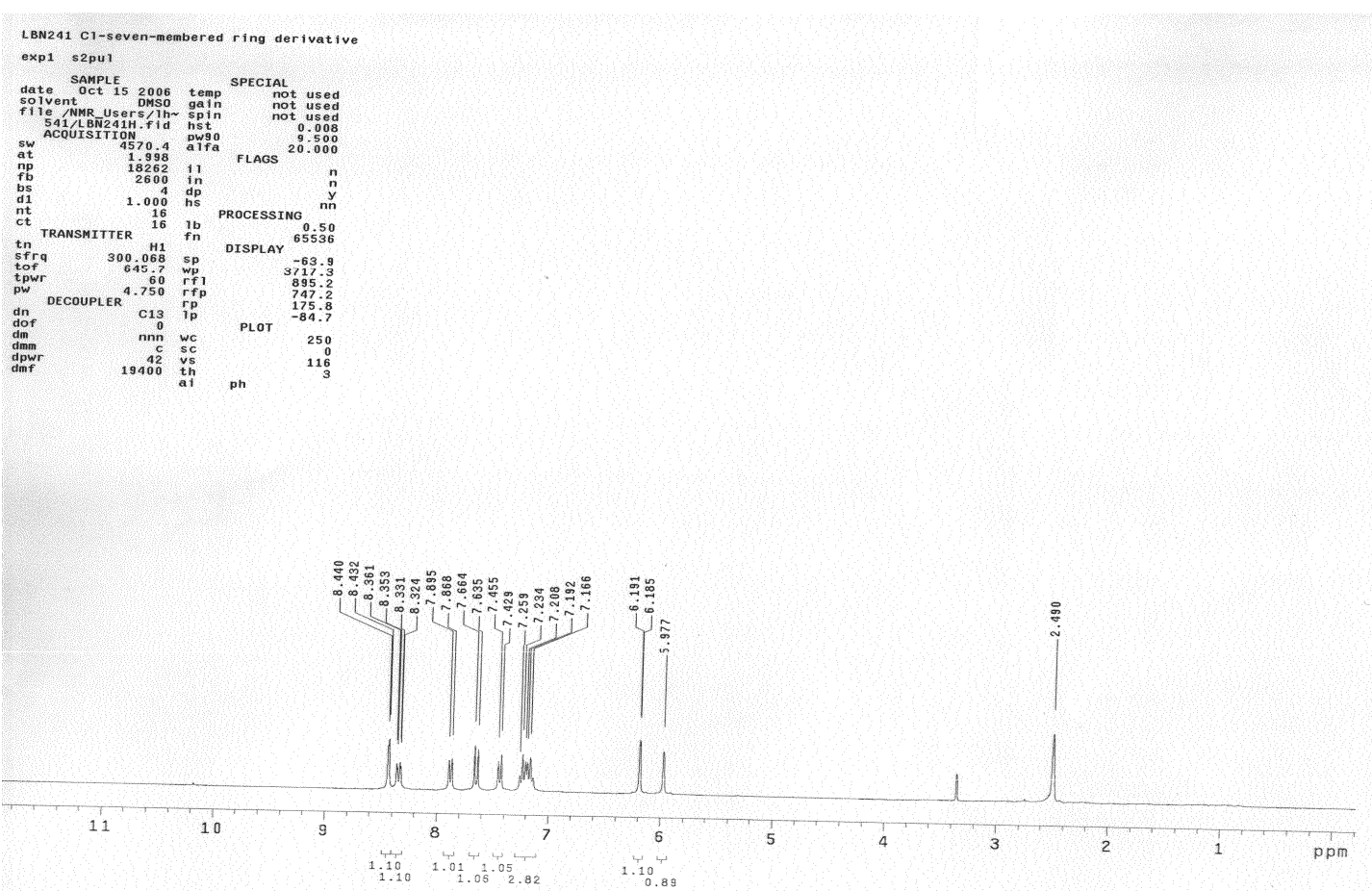

เะм241

exp3 sta1sc

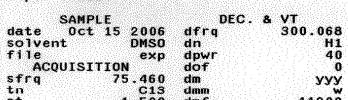

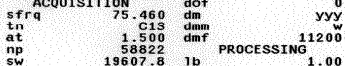

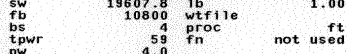

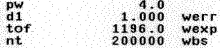

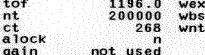

in Finost used

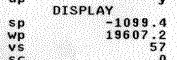

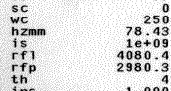

tins 1.000

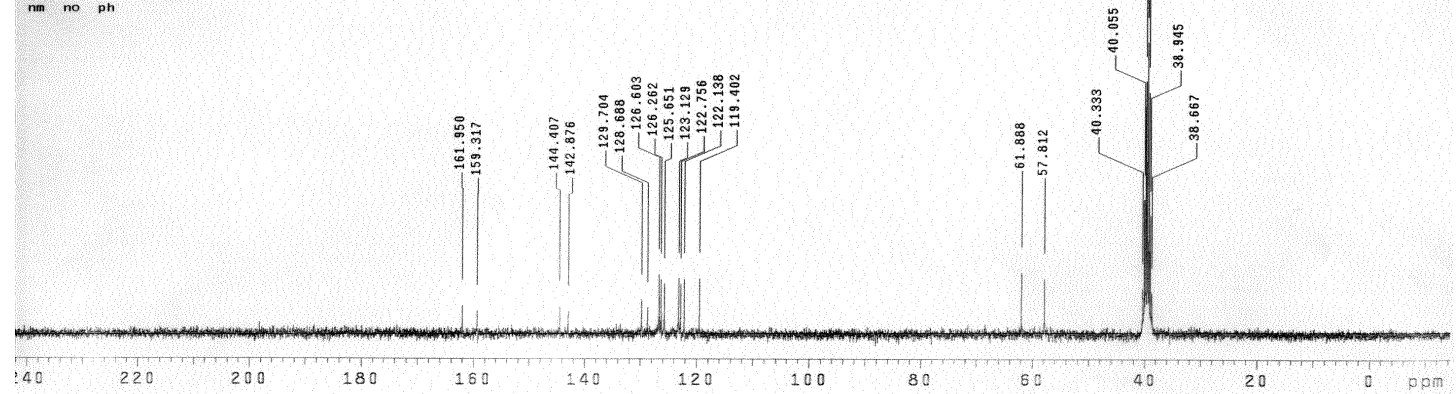


$( \pm)-$ trans $^{-4}-$ Nitro-2-phthimido-azeto $[1,2-d]$ dibenzo $[b, f]$ oxazepin-1-one $(25 c)$

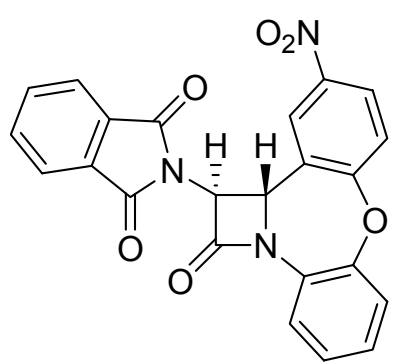

$(\underline{+})$

LBN159 PhthN-CImine-NO2 $1500 \mathrm{C}$

exp1 s2pu1

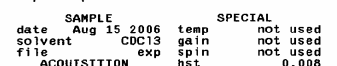

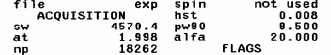

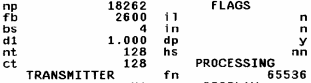

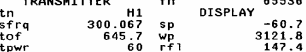

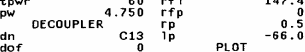

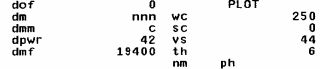

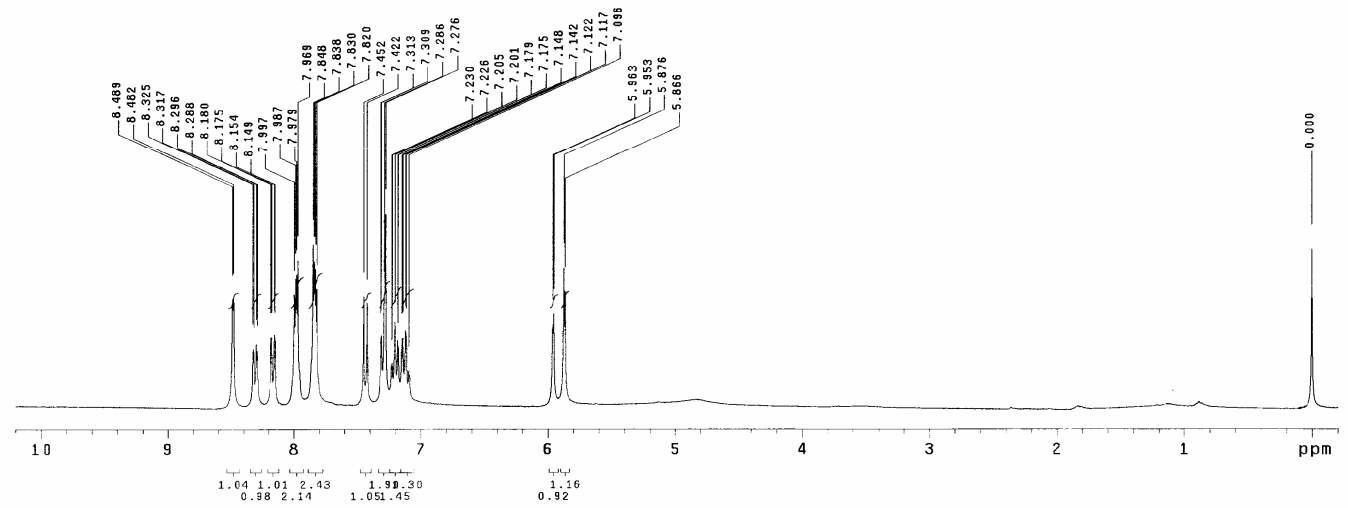

LBN159 PhthN-CImine-No2 $1500 \mathrm{C}$

exp3 std13c

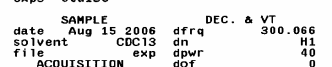

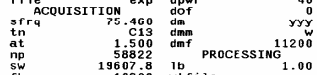

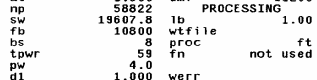

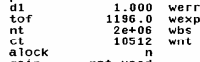

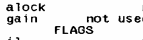

西

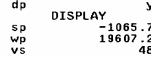

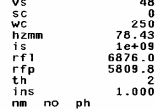
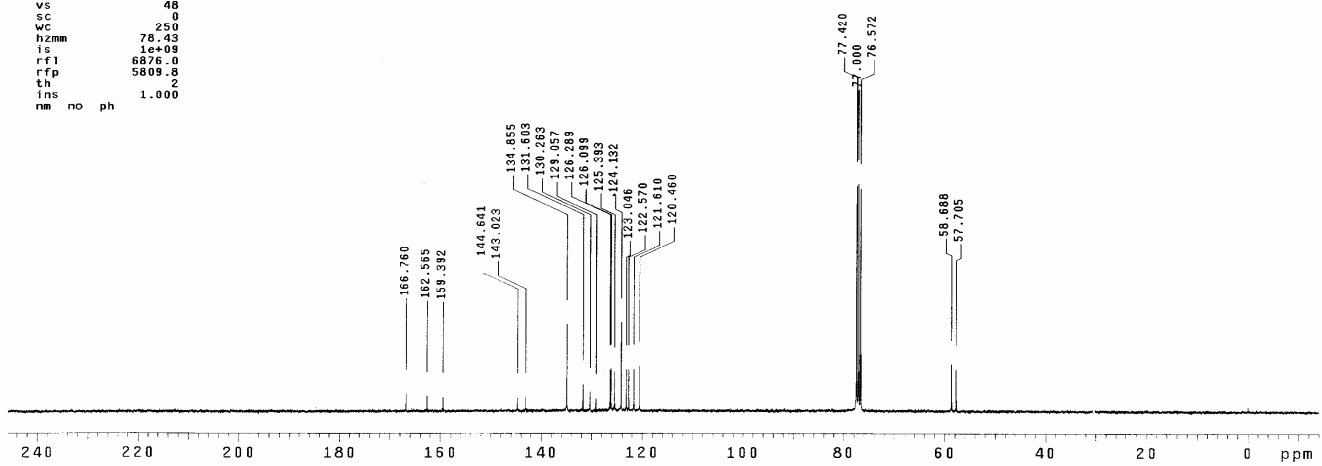
Copies of the Representative ${ }^{1} \mathrm{H}$ NMR Spectra for Determination of Cis/Trans Ratios<smiles>CCCN1C(=O)[C@H](C)[C@H]1c1ccc([N+](=O)[O-])cc1</smiles>

$( \pm)-c i s-3$

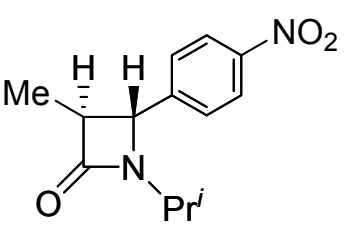

(士)-trans -4

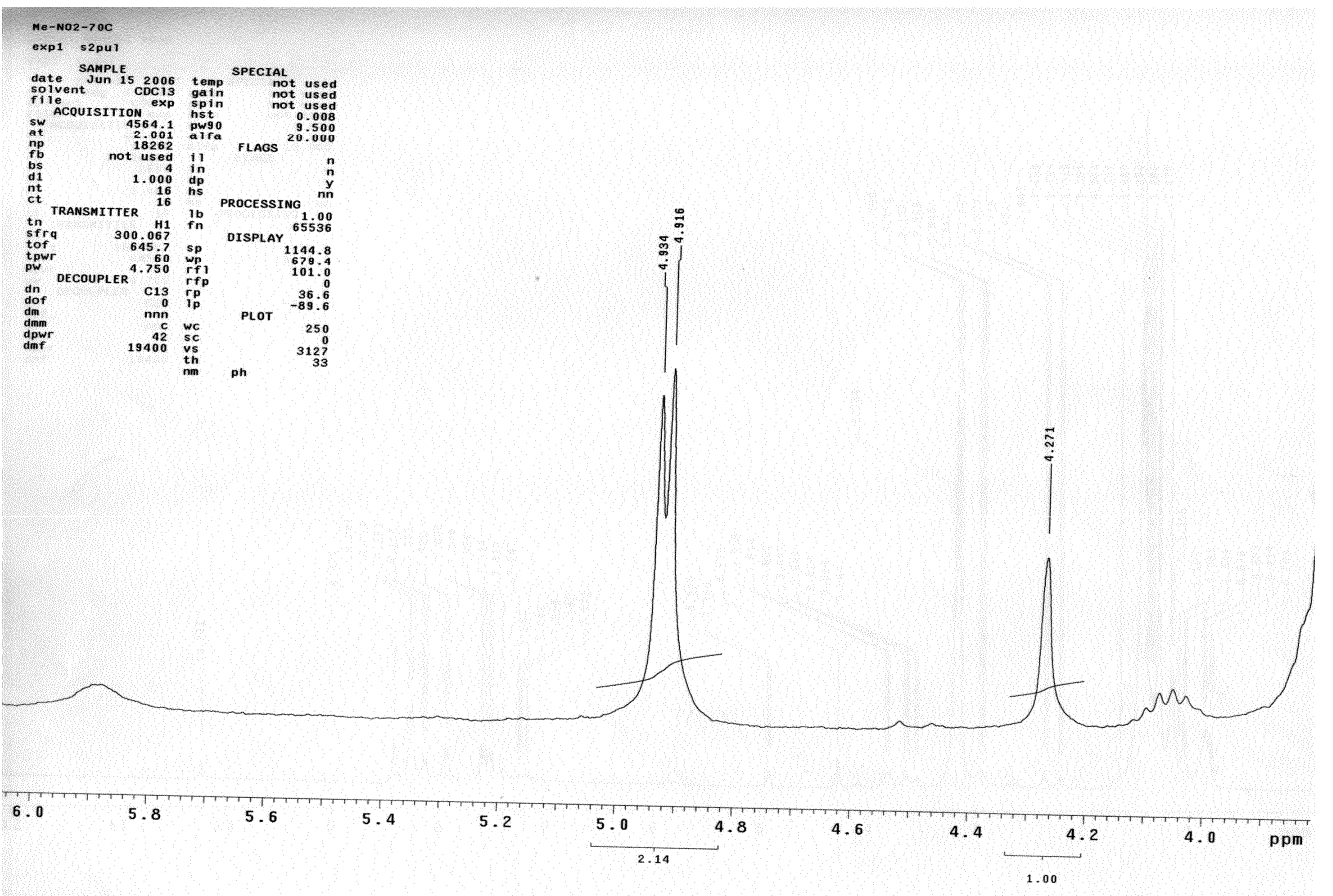<smiles>CCCN1C(=O)[C@H](c2ccccc2)[C@H]1c1ccc([N+](=O)[O-])cc1</smiles>

( \pm - cis - 5

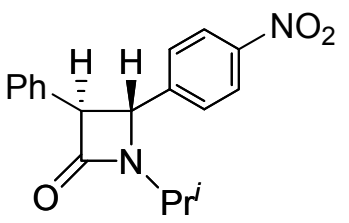

( \pm )-trans -6

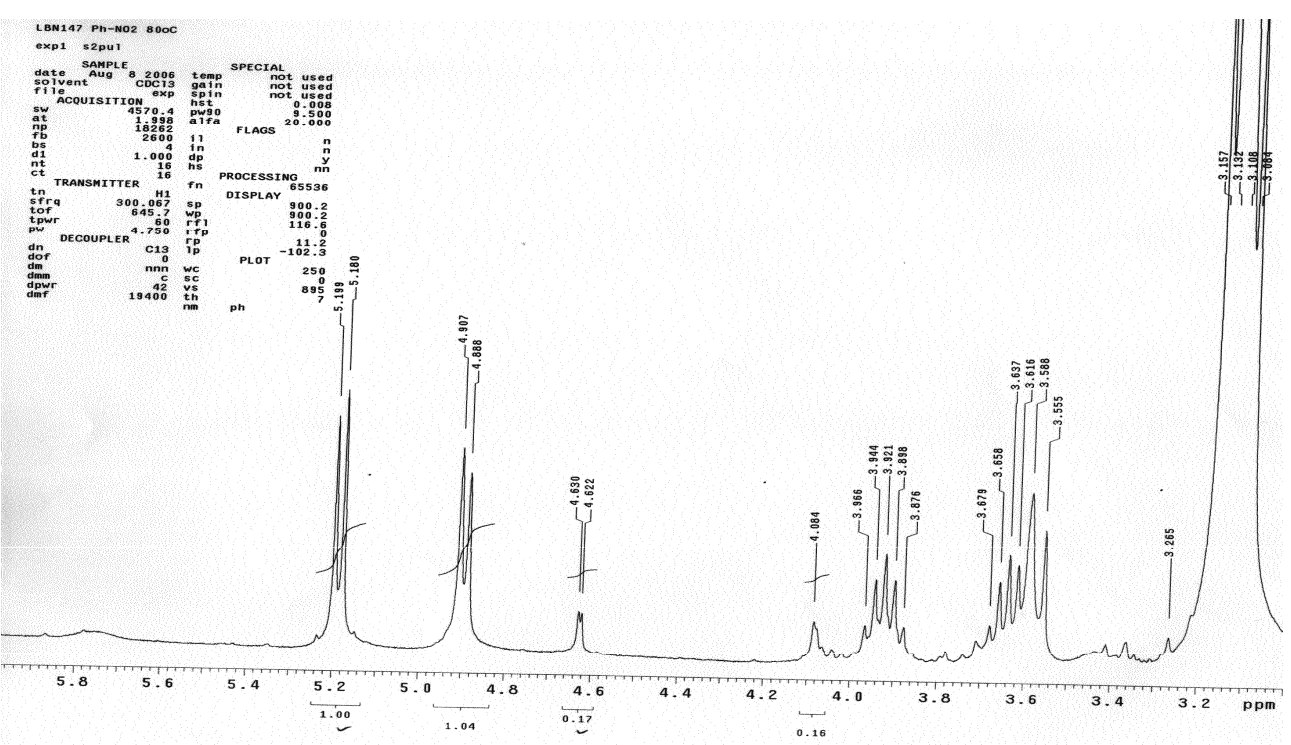




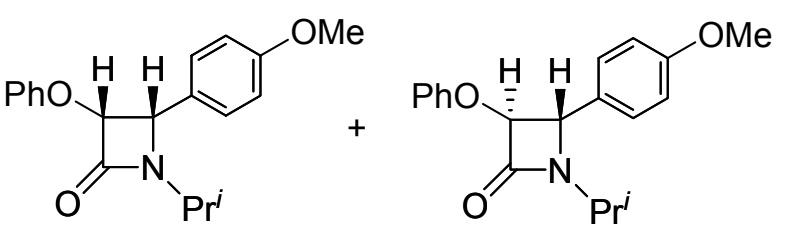

( \pm )-cis -7

(士)-trans -8
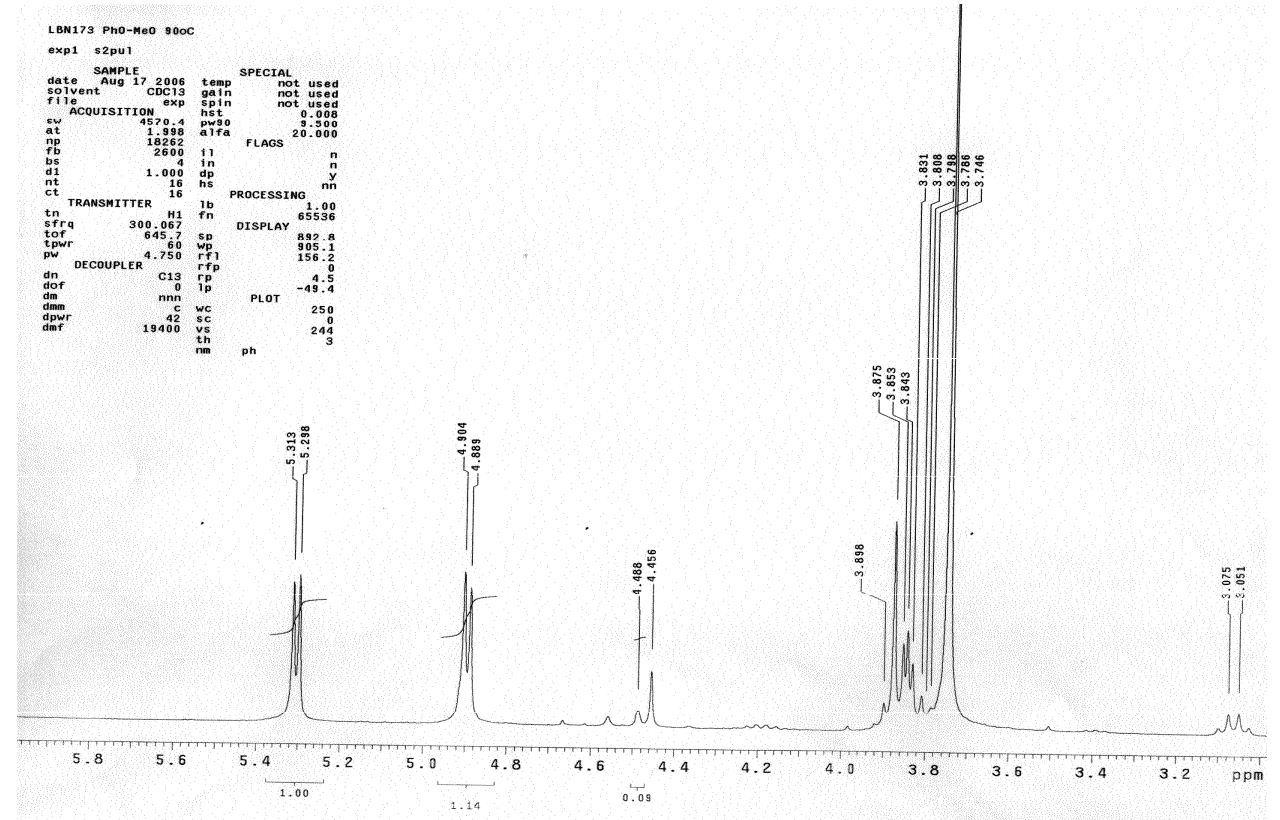<smiles>CCCN1C(=O)[C@H](Cl)[C@H]1c1ccc([N+](=O)[O-])cc1</smiles>

$( \pm)-c i s-9$

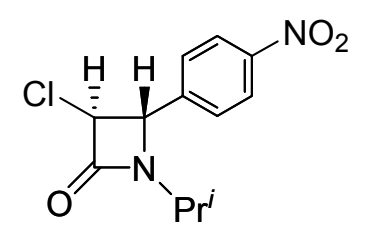

( \pm )-trans -10
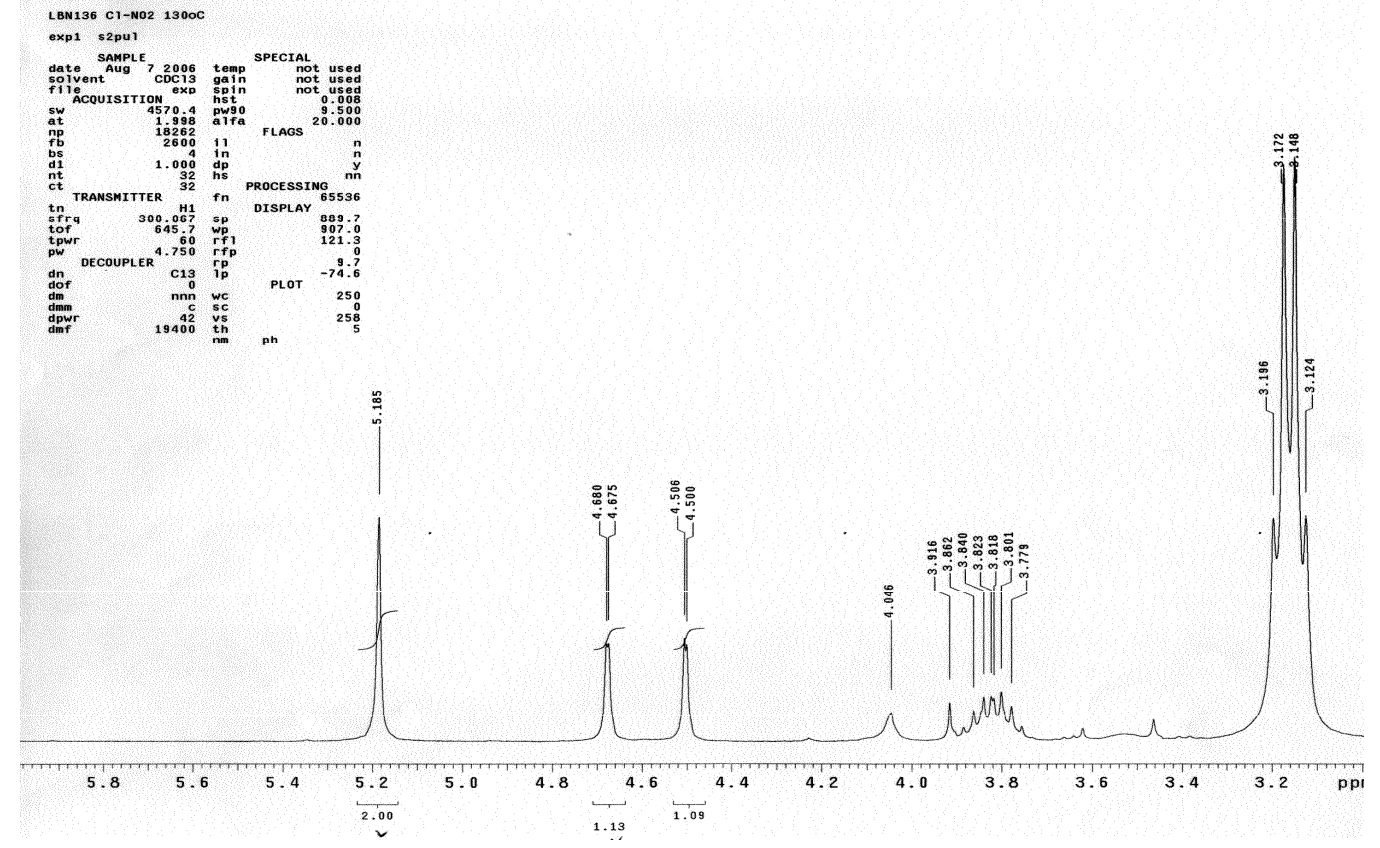


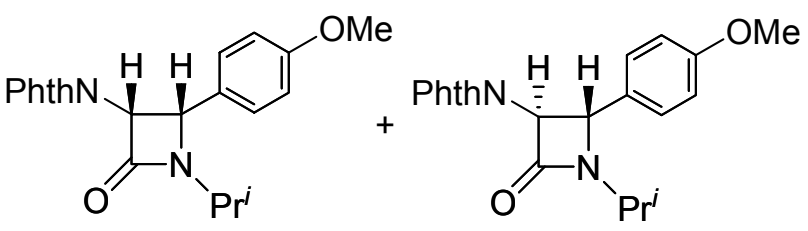
$( \pm)$-cis - 11
(士)-trans-12
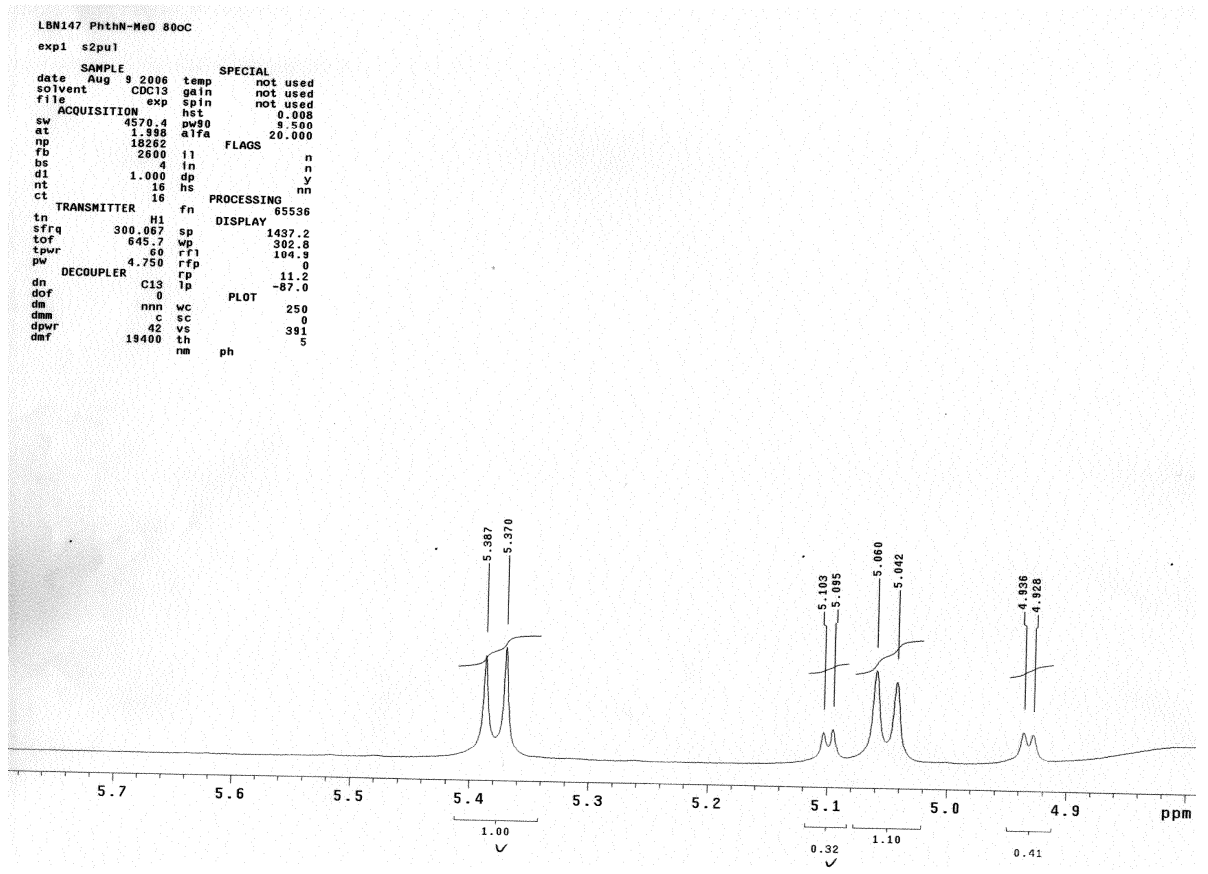<smiles>CCCPN1C(=O)[C@H](c2ccc([N+](=O)[O-])cc2)[C@@H]1c1cc([N+](=O)[O-])ccc1[C@@H]1[C@@H]([PH2+])C(=O)N1CCC</smiles>
$( \pm)-$ cis -13
( \pm )-trans -14
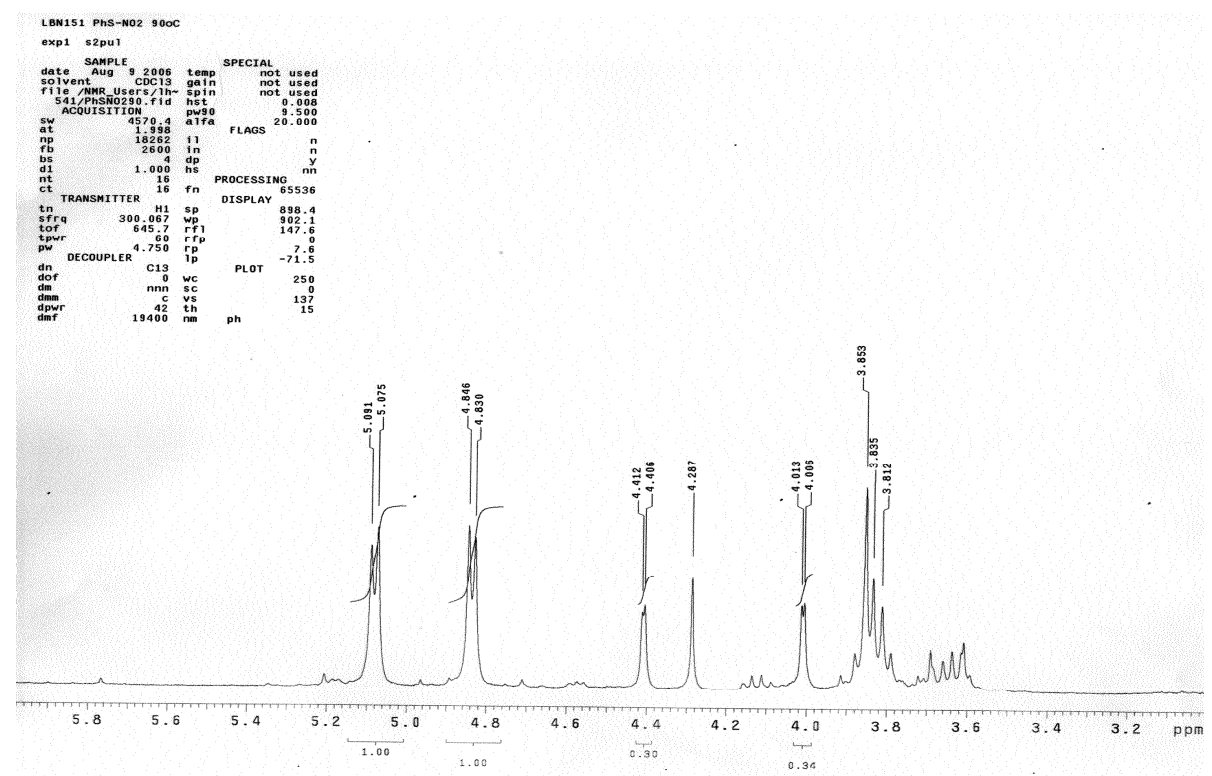


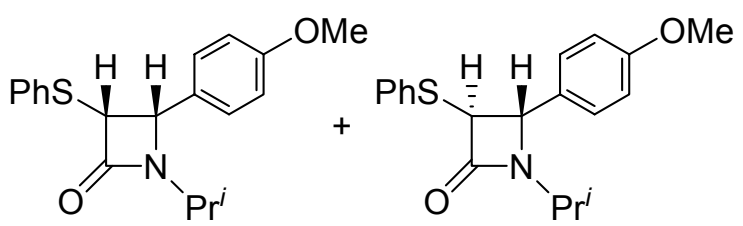
(士)-cis -15
(士)-trans -16
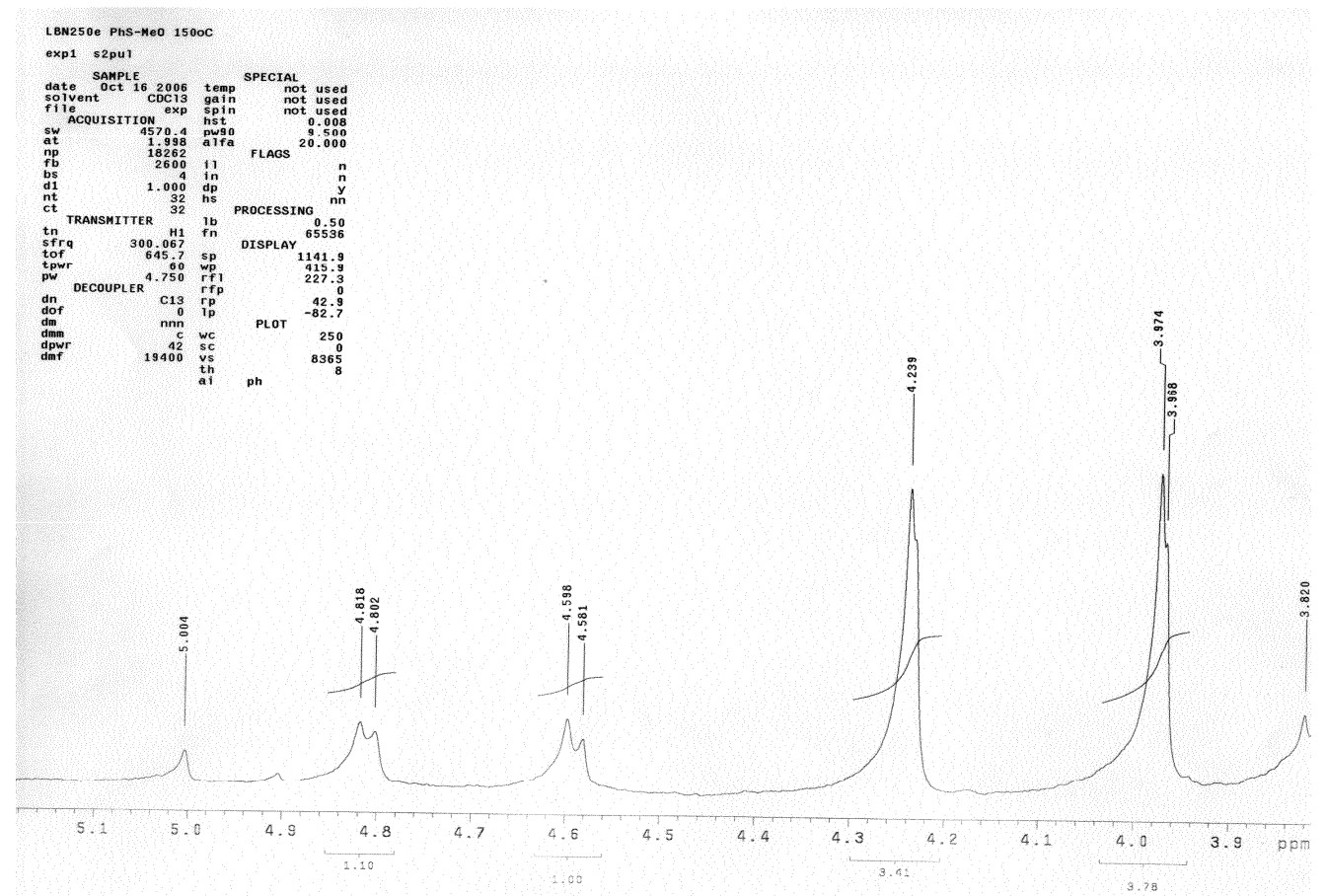<smiles>CCCN1C(=O)[C@H](c2ccc(OC)cc2)[C@H]1c1ccc(OC)cc1</smiles>

$( \pm)$-cis - 17

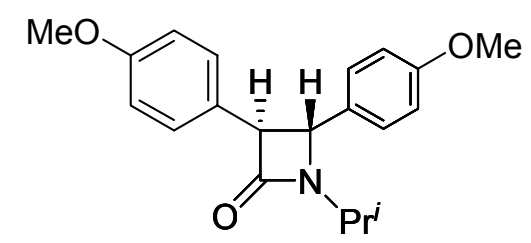

( \pm )-trans -18
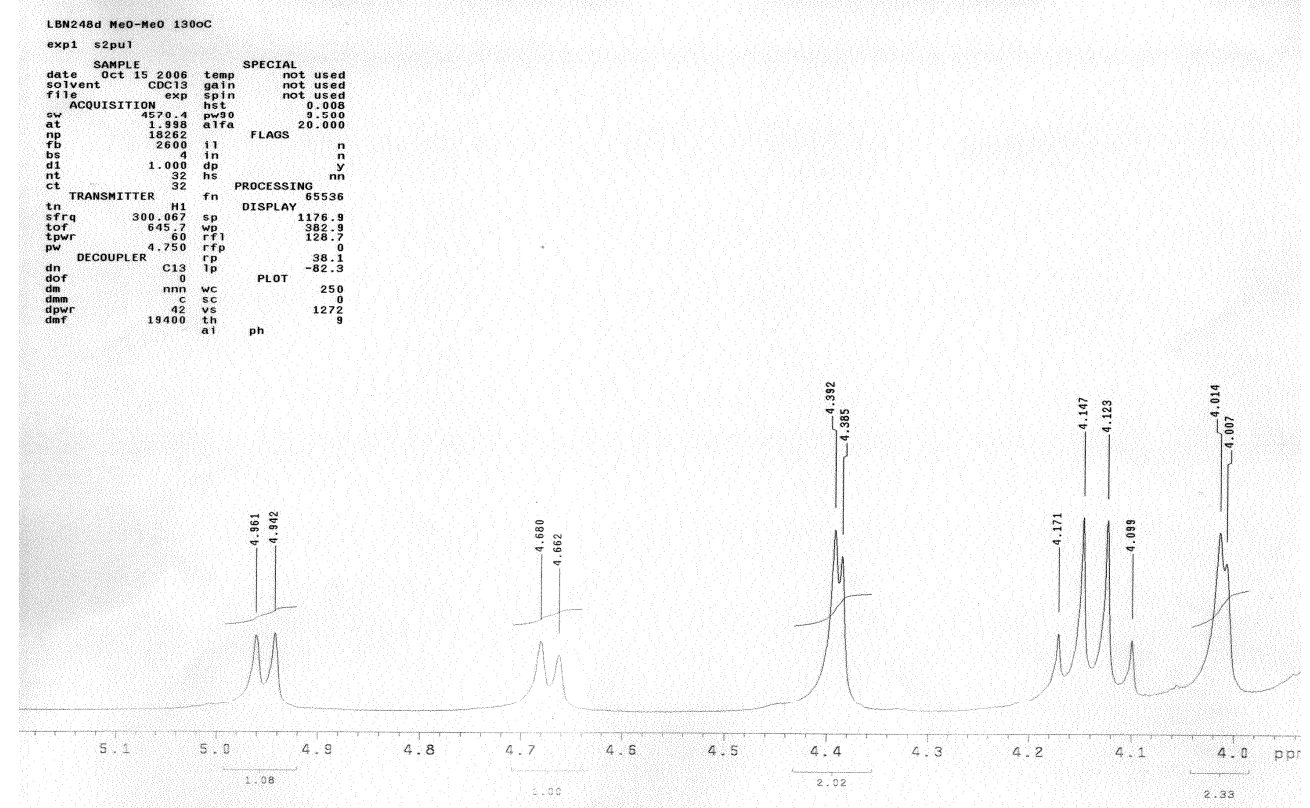
<smiles>CCCN1C(=O)[C@H](c2ccccc2)[C@H]1c1ccc(OC)cc1</smiles>

(士)-cis - 19

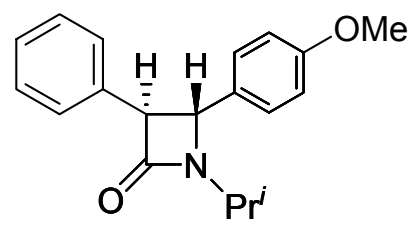

(士)-trans -20
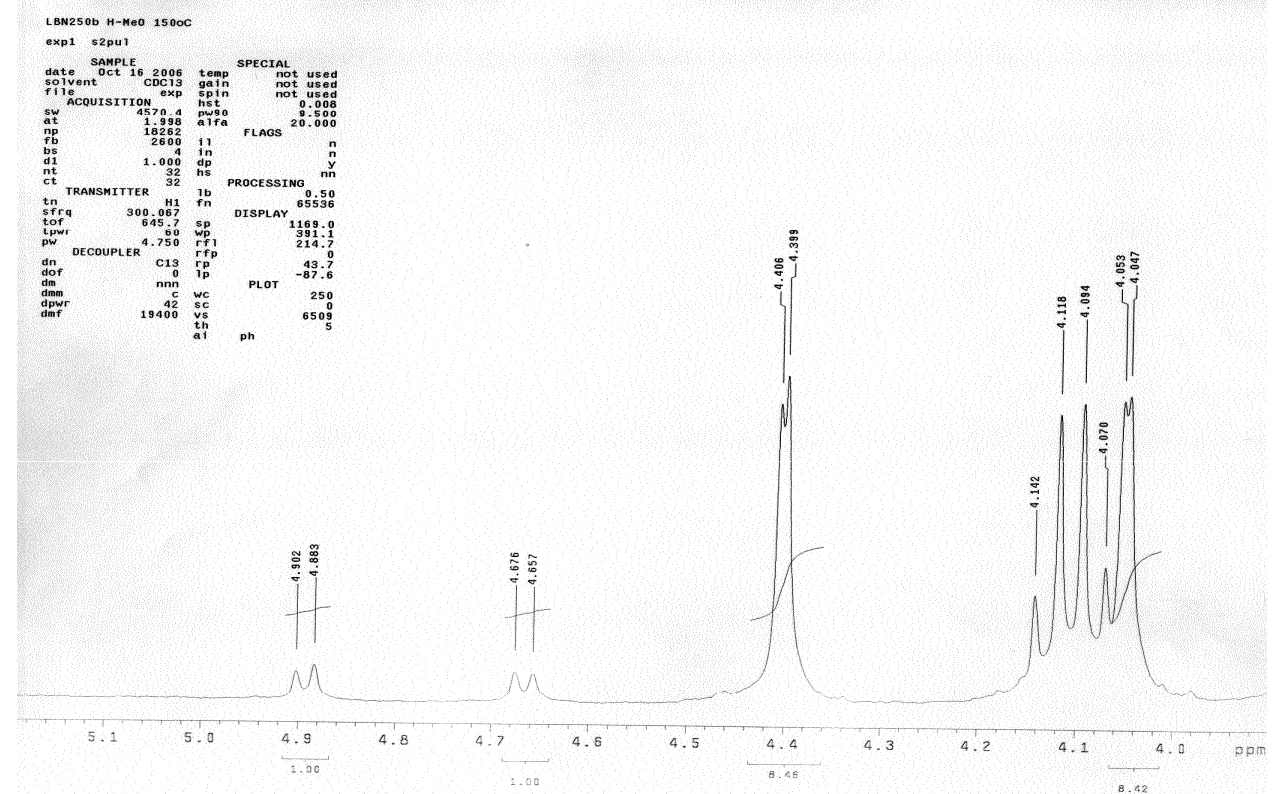<smiles>CCCN1C(=O)[C@H](c2ccc([N+](=O)[O-])cc2)[C@H]1c1ccc(OC)cc1</smiles>

(士)-cis - 21

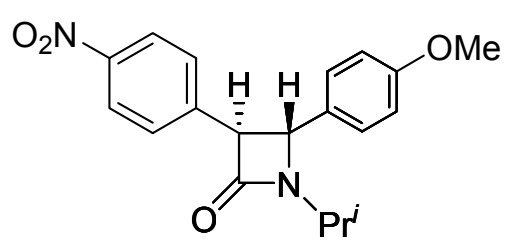

(土)-trans -22
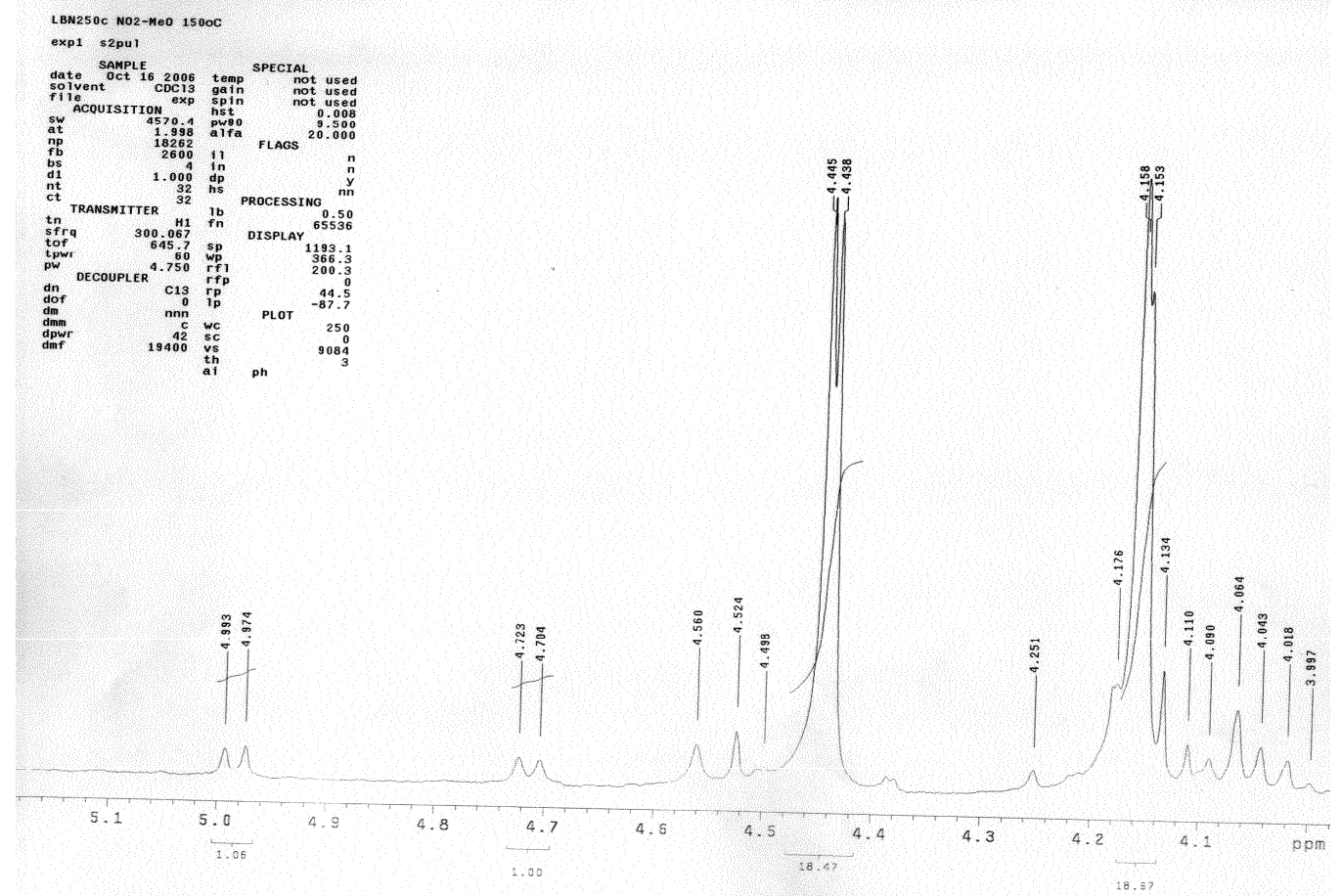
<smiles>CCCN1C(=O)[C@H](c2ccc([N+](=O)[O-])cc2)[C@H]1c1ccc([N+](=O)[O-])cc1</smiles>

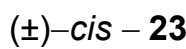

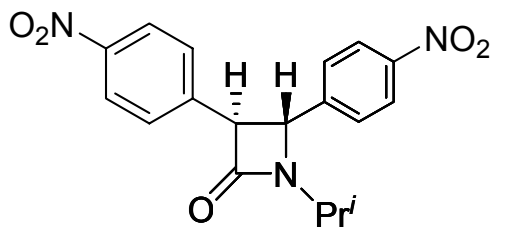

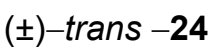
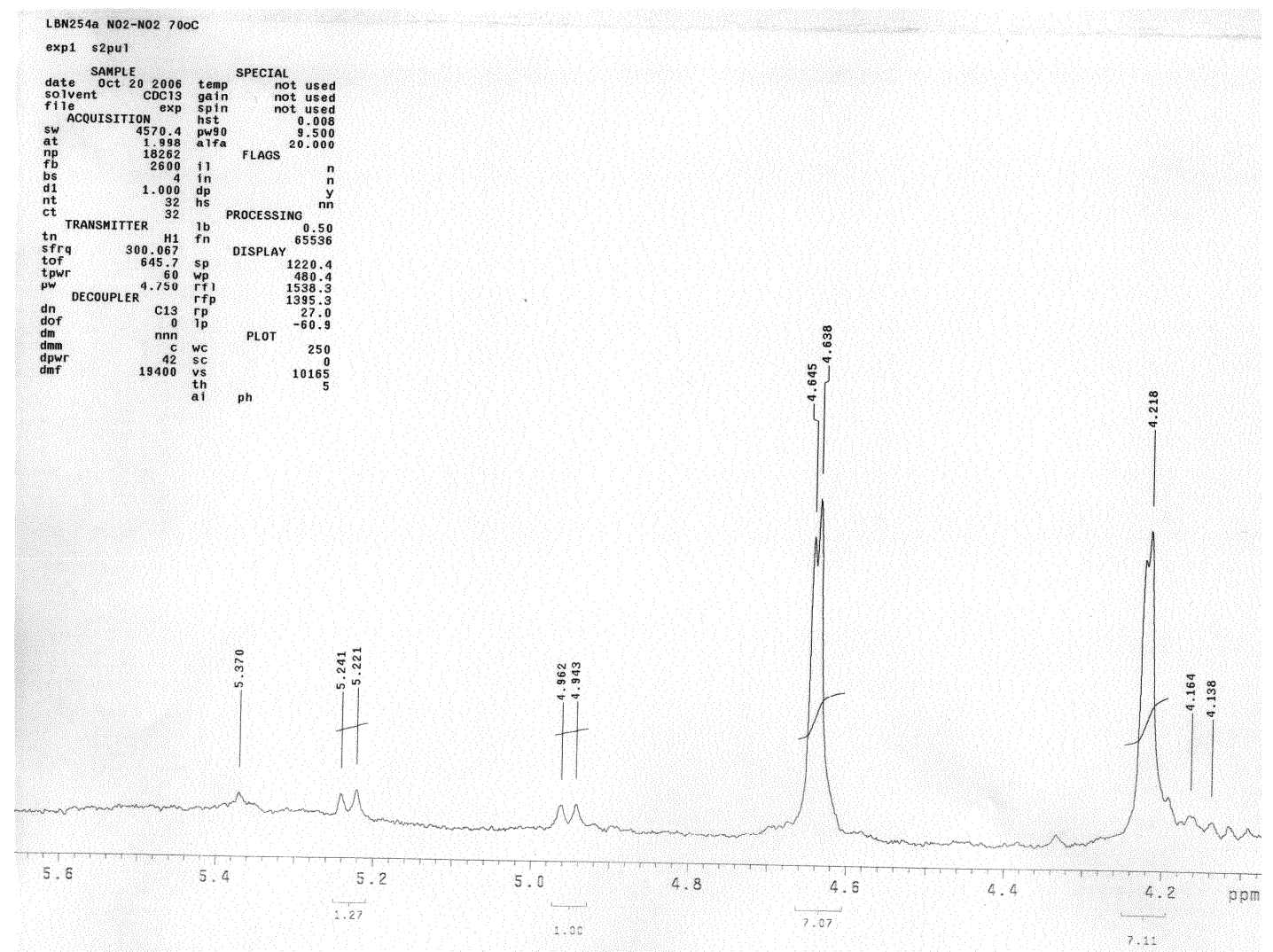